\title{
EVALUATION OF ANCHORAGE INTERNATIONAL AIRPORT USING THE AIRPORT BUSINESS SUITE

\author{
P.C. Roling
} \\ Delft University of Technology, the Netherlands
}

Keywords: ANC, Airport, Airside, Capacity, Noise

\begin{abstract}
In this paper, the effect of growth in both passenger numbers and cargo will be examined for Ted Stevens Anchorage International Airport (ANC), one of the busiest cargo hubs in the world. For this the possibility of including growth of the cargo market has been added to the Airport Business Suite (ABS).

Results for ANC show that, as a result of the traffic forecasts made in the airport master plan, the average aircraft size will increase due to the large relative growth of the cargo market. As a result of the additional traffic, an extra runway parallel to 14/32 will be needed in 2025 , but an extra runway parallel to the $6 / 24$ will probably not be necessary.
\end{abstract}

\section{Introduction}

After the initial dip in traffic 9-11 caused, growth in demand for air travel is now as high as ever, causing more and more congestion at major airports. While some airports around the world do have some possibilities to expand, like Atlanta Hartsfield international airport (ATL) which has just taken its fifth runway into operation, other airports do not have the space, either physically or in regulations, to do this. Currently this often results in traffic diverting to secondary airports.

As demand for air travel grows, Boeing Commercial aircraft expects that frequencies of flights will increase, and airports will expand where possible. Especially the advent of low cost carriers seems to support this type of growth. Airbus, on the other hand, expects that traffic to major population centers with congested airports will often require larger aircraft. A good example of this is slot restricted London Heathrow which will see the bulk of A380 operations as they are delivered to customers for commercial flights.

At the ATIO 2006, research [1] was presented on a study at the effects of changes in the average size of aircraft will have on the airport in terms of delay, passenger flows and noise at Atlanta Hartsfield-Jackson international airport, the worlds busiest airport in passenger numbers. Subsequent research [2] was presented with respect to London Heathrow, which has a substantially different traffic pattern and is currently far more congested. This research will be about a large cargo airport, Ted Stevens Anchorage International Airport and for the first time take a look into the effects of cargo operations on airport capacity.

\section{The Airport Business Suite}

In order to allow airports to do assessments of future scenarios and get an idea of required strategies to cope with these scenarios, the Technical University of Delft developed the Airport Business Suite (ABS), a decision support system for airport strategic exploration [3]. The ABS is currently used mostly for educational purposes in an MSc course named 'Strategic Planning for Airport Systems' [4] in which students at the Delft University of Technology have to model a US airport and define a strategy for it.

The ABS has a number of models which are combined through a common data layer and user interface. One of these models is the flight schedule generator, which creates peak day flight schedules and allows the user to easily adapt them for possible future scenarios. The 
airside capacity and delay model, which is based on the FAA airfield capacity model, is used to calculate the effect a peak day flight schedule will have. The ABS also includes a terminal capacity model and a noise data model to export data for use in the Integrated Noise Model (INM). All data, including airport and aircraft data, is stored in a Microsoft Access or SQL databases.

Through the last couple of years, a number of improvements have been made to the ABS, both with respect to usability and additional features [5]. A major recent change in the ABS is that the stochastic queuing model, which calculated the arrivals and departures as flows, has been changed to a discreet model, which calculates landing and departure times per individual flight. To simulate the effects of varying arrival and departure times, which was captured by the stochastic model, the model is now run a number of times with a variation in the random seed used for the basis of the normal distribution applied to the arrival and departure times.

For this paper, evaluation of the cargo market growth in the flight schedule generator has also been added, allowing the effects of growth in the air cargo market to be evaluated with respect to airside capacity.

\section{Ted Stevens Anchorage International Airport}

Anchorage International Airport (ANC) was built in 1951 and renamed in 2000 to include the name of the long-standing senator Ted Stevens. During the cold war it was a common stopover for aircraft flying to eastern Asia, as aircraft from western nations were not allowed to over fly soviet airspace. Whilst some passenger aircraft still use ANC, it is now primarily used for cargo flights between North America and Eastern Asia.

With respect to passenger traffic, Alaska Airlines has its second largest hub there, with most passengers flying to its primary hub Seattle. With respect to cargo, Federal Express, United Parcel Service and Northwest Airlines Cargo have large hubs at ANC. The United States Postal Service operates a large sectional facility for Alaska. In 2007 it was the third

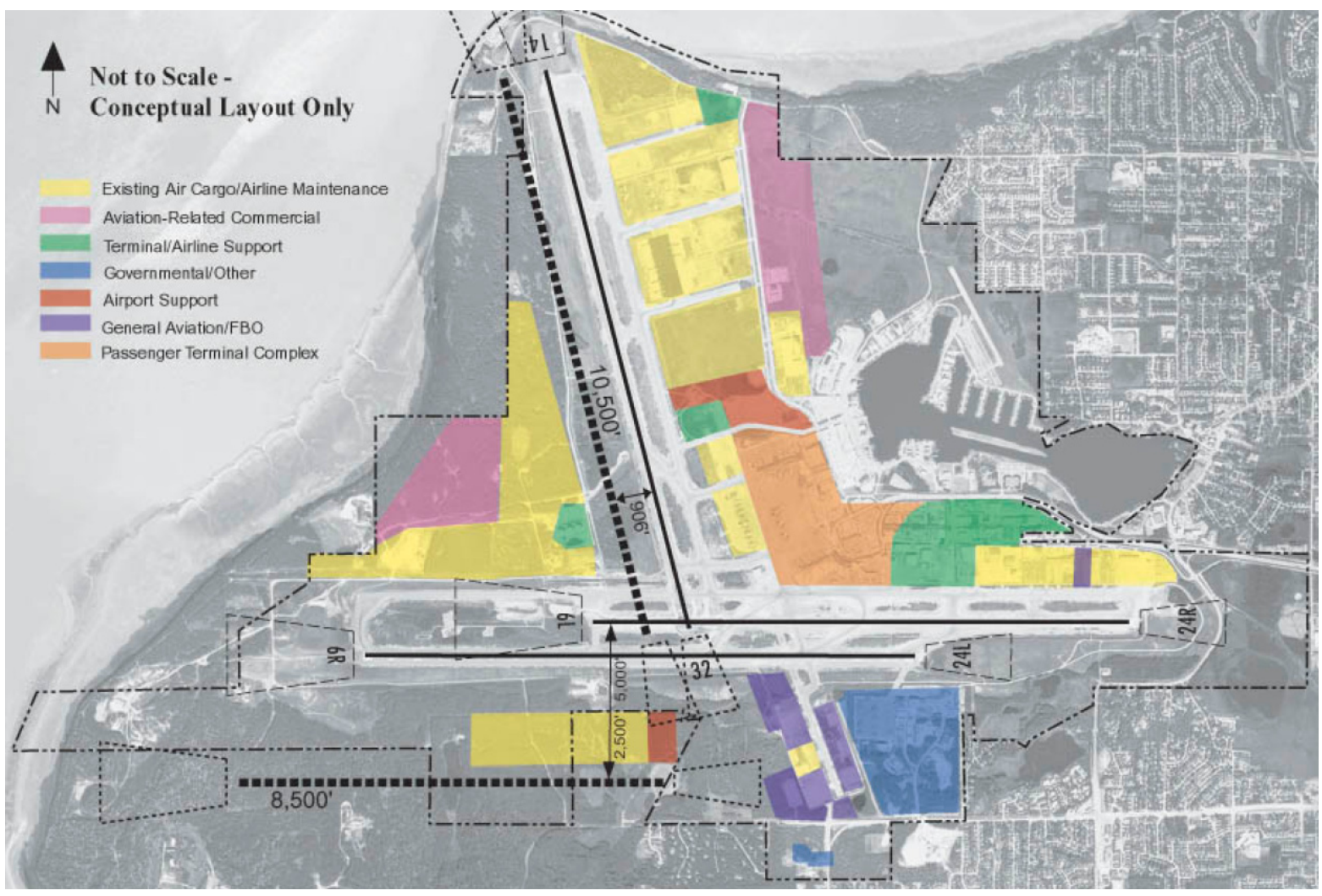

Fig. 1: Anchorage possible future runway layout 
busiest airport in the world with respect to cargo, after Memphis and Hong Kong [8].

With respect to passenger enplanements and deplanements, an average yearly growth of 1.1 percent is predicted [7], which can be considered as very low, even for US standards where the average growth nationwide is expected to be around 3 percent. This is mostly caused by an expected decrease in transit passengers as the need for technical stops between Asia and North America decreases due to advent of longer range aircraft.

For cargo the expected yearly growth averages to 6.1 percent per year, showing that cargo will become more and more the major business case for the airport. One of the main reasons for this is that the range of cargo aircraft is usually much more limited due to the relatively high payload weights involved, which limit the amount of fuel which can be carried. For example, the 747-8 passenger version has a range of $14,815 \mathrm{~km}$, whilst the $747-8$ freighter has only a range of 8,275 kilometers.

There are a number of new runway options laid out in the master plan [6] for the future, most notably an extra runway in the northwestsoutheast direction and an extra runway in the east west direction, as shown in Fig. 1.

\section{Scenarios}

Separate from the base year, a number of different peak day scenarios are looked at for the year 2025. For this study only the effect of using larger aircraft will be looked at.

Table 1 shows summaries of the base case and a number of future scenarios. The scenarios listed assume a 1.1 percent growth in passenger numbers and an average growth of 6.1 percent per year for cargo, as is forecasted in the airports master plan [7], with different percentages of the growth accomplished by using larger aircraft. As can be seen in Table 1, a higher aircraft growth percentage allows the number of flights to decrease whilst

Table 1: Summary of peak day scenarios

\begin{tabular}{|c|c|c|c|}
\hline Scenario & Flights & Pax & Freight (ton) \\
\hline Base 2005 & 569 & 22265 & 20335 \\
\hline $20250 \%$ ACG & 1241 & 27582 & 66599 \\
\hline $202510 \%$ ACG & 1161 & 27366 & 66494 \\
\hline $202520 \%$ ACG & 1093 & 27241 & 66525 \\
\hline $202530 \%$ ACG & 1033 & 27252 & 66413 \\
\hline $202540 \%$ ACG & 1005 & 27333 & 66511 \\
\hline
\end{tabular}

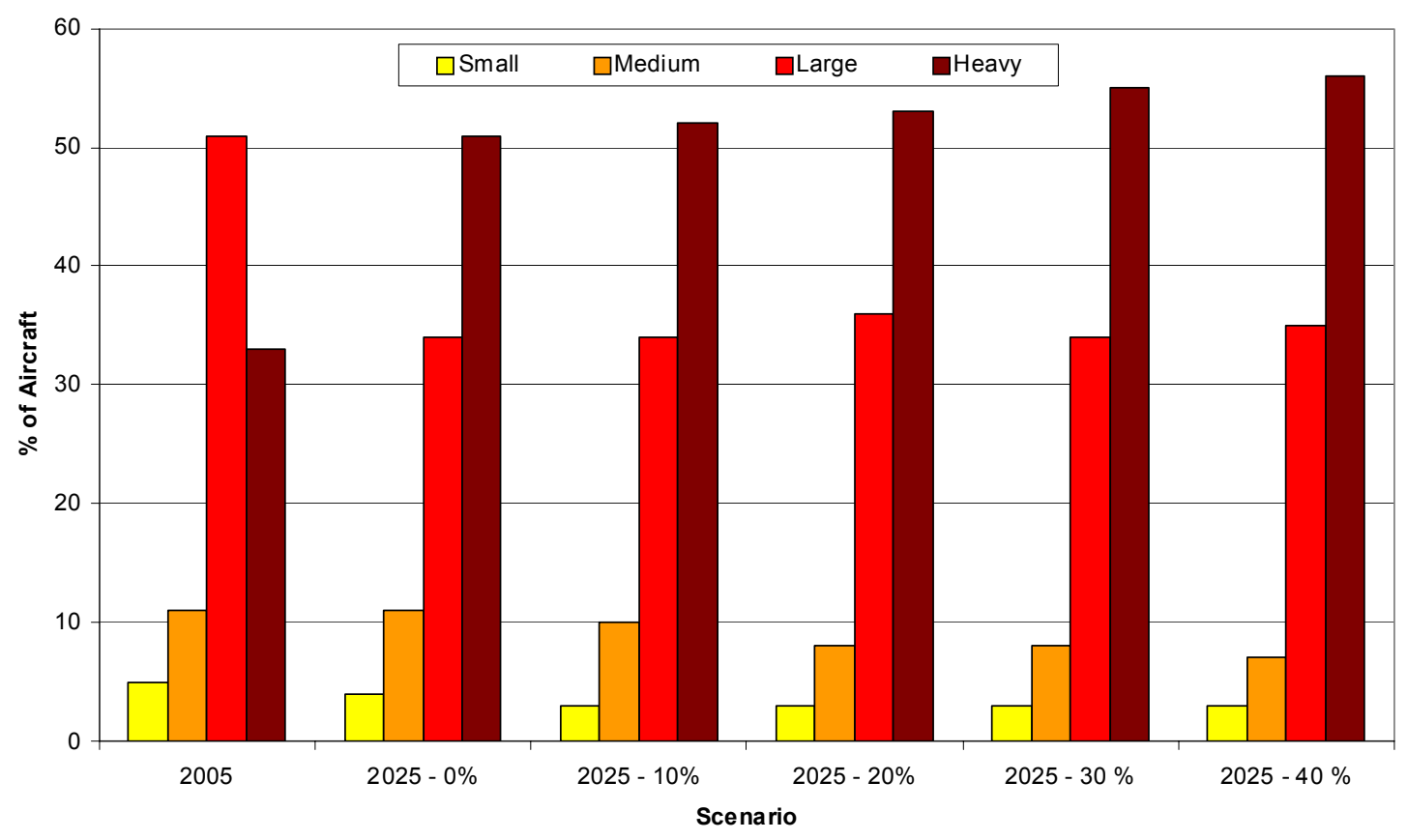

Fig. 2: Aircraft weight class distribution 
accommodating about the same amount of passengers and cargo. The main downside to the reduced number of flights is, off course, the decrease in frequencies to the connected airports.

The effect the scenarios have on the distribution of weight classes is shown in Fig. 2. One main phenomenon which can be observed here is that the number of heavies is significantly larger for all the scenarios, regardless of the aircraft growth. This is due to the high growth in cargo compared to the growth in passengers and the fact that most cargo flights to and from ANC use heavy aircraft, such as the 747, DC10 and the MD11, whilst the majority of passenger flights are done using large aircraft, such as the MD80, 737 and the A320. The effect of aircraft growth is also visible, mostly in the form of a reduced number of aircraft the medium category, compared to aircraft in the heavy category.

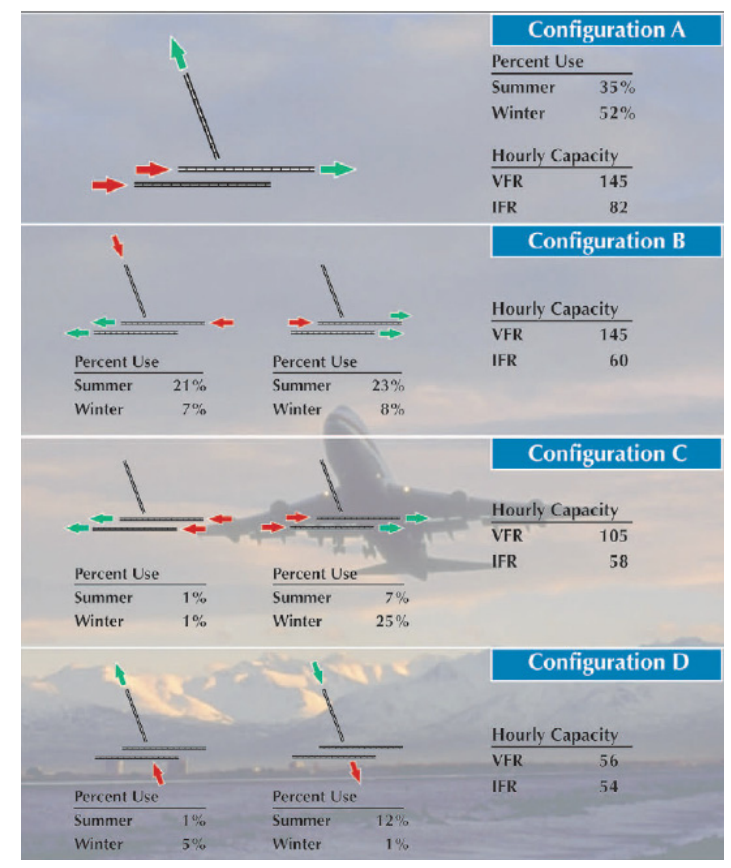

Fig. 3: Runway configurations

\section{Airside capacity}

Currently ANC has three main runways, each with a width of 150 feet and a length of over 10,000 feet, allowing all aircraft types to use them. Two of these runways are closely spaced parallels in an east west direction, allowing near independent arrivals on one runway and departures on the other during visual flight rules (VFR) under visual meteorological conditions (VMC). A possible parallel runway to the south is envisioned. The other current runway, 14-32, is in a northwestsoutheast direction and is planned to have an additional parallel runway laid next to it in the future.

Fig. 3 shows the current four main runway configurations which are used according to the master plan. The main configurations which will be evaluated here are configurations $\mathrm{C}$ and $\mathrm{D}$, as these are the most capacity restraining, especially during the winter. With the additional of an extra parallel north south runway, the capacity of configuration D should increase rapidly, as it would also allow parallel operations, similar to configuration $\mathrm{C}$.

In $\mathrm{ABS}$ the following runway configurations are defined for the base year, which are used throughout the day:

- 06: Runway 06L is used for arrivals and 06R for departures.

- 14: Runway 14 is used in mixed mode.

- 24: Runway 24L is used for arrivals and 24R for departures. Results are identical to 06 .

- 32: Runway 32 is used in mixed mode. Results are identical to 14 .

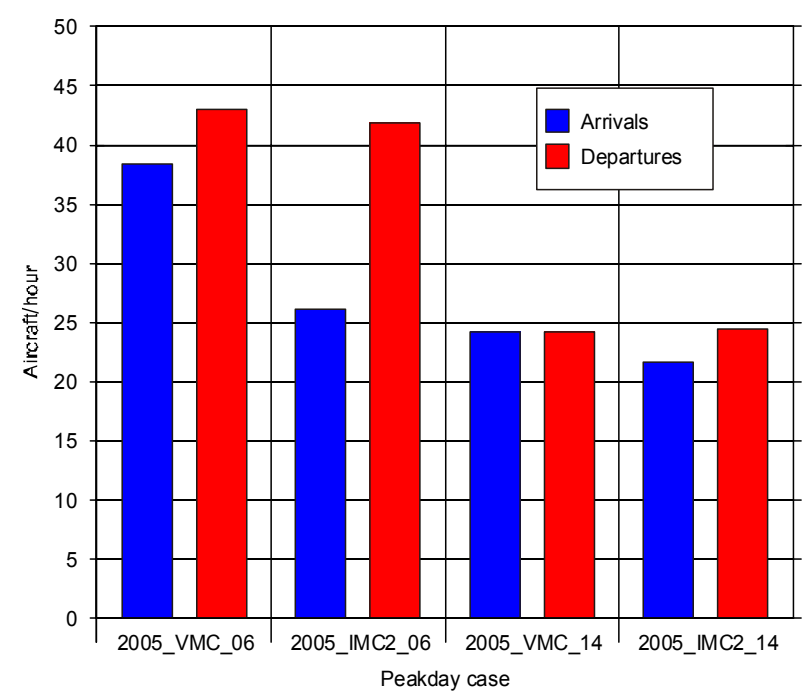

Fig. 4: Capacity in the base year

Using configuration 06 , or 24 which has an identical capacity, in the base year results in an average total capacity of just more than 80 
operations per hour under $\mathrm{VMC}$, as shown in Fig. 4. It should be noted that the declared capacity numbers in Fig. 3 are the maximum arrival and departure capacity numbers, where the ABS uses the average numbers, which are naturally lower. During instrument flight rules (IFR) under instrumental meteorological conditions (IMC) arrival capacity drops quite

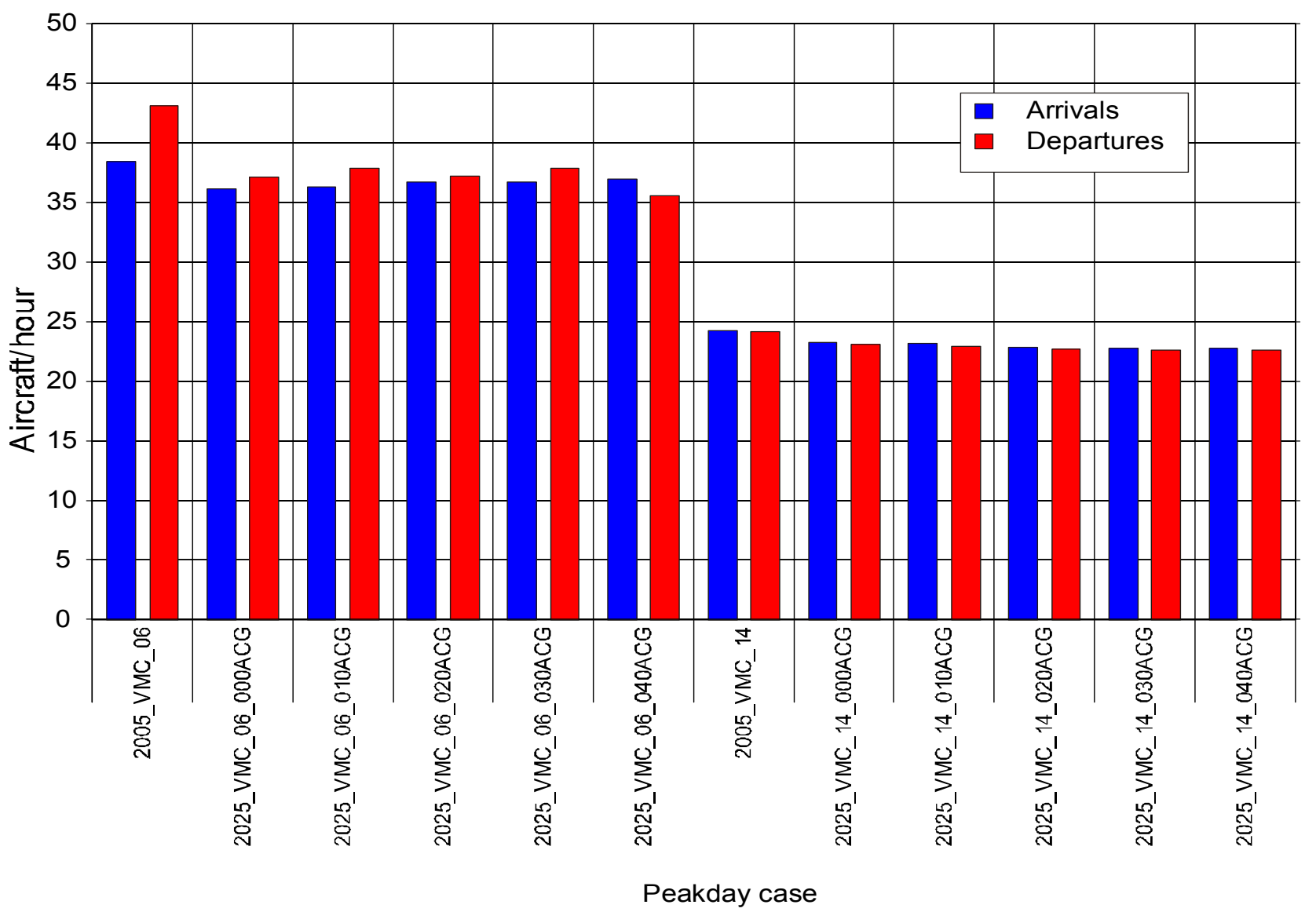

Fig. 5: Current and future airside capacity for different aircraft growth percentages.

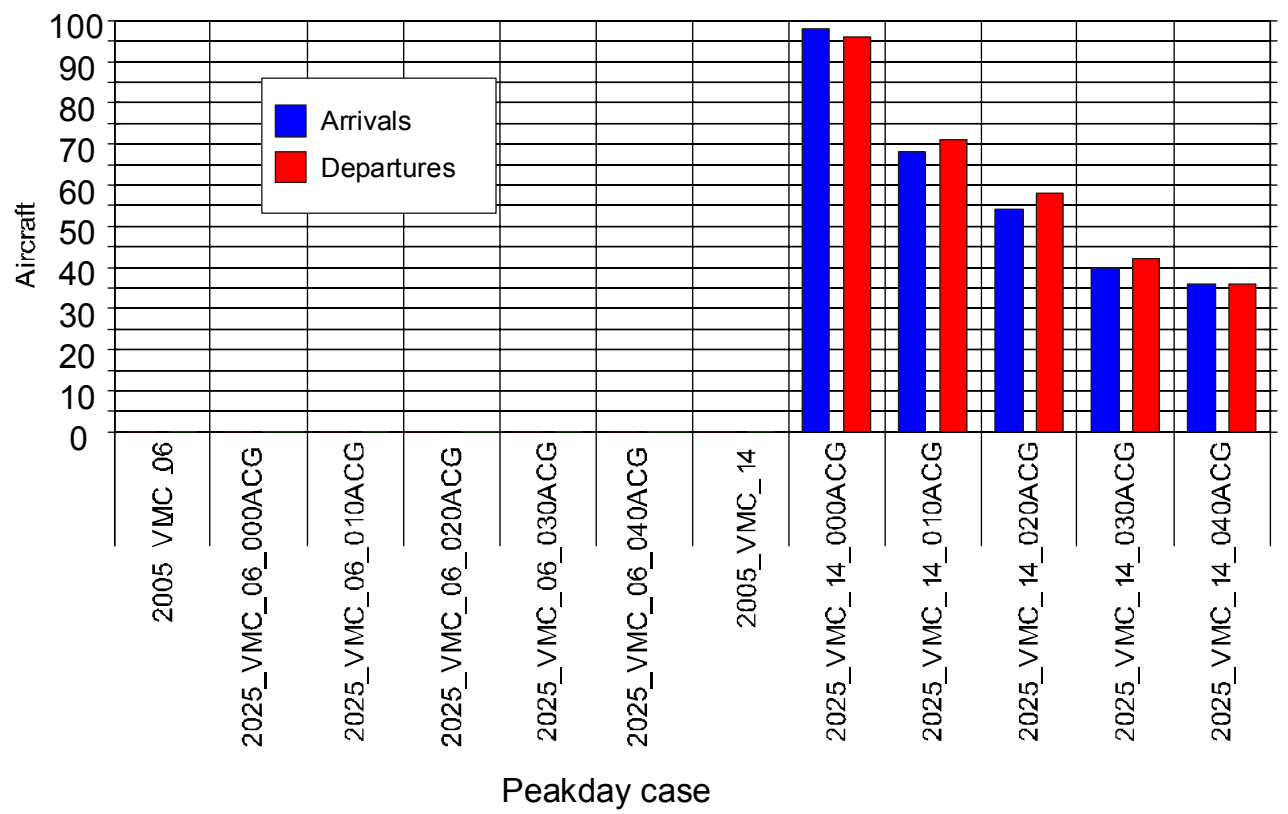

Fig. 6: Flights cancelled due to excessive delay ( $>30$ min) 
dramatically. Using configuration 14 (or 32) in the base year results in an average runway capacity of almost 50 operations per hour, which reduces to about 45 operations per hour in IMC.

In Fig. 5 the capacity for runway configurations 06 and 14 is shown for VMC conditions. Especially for configuration 06 the capacity for all the future scenarios is significantly reduced due to the increase in average aircraft size. The differences in capacity between the different aircraft growth scenarios are relatively small and mostly caused by small changes in the average arrival separation due to changes in the weight class mixture.

\section{Airside Delay}

The effect of the runway capacity for the different scenarios is shown in Fig. 6. Most notably, only a single runway $14 / 32$ will not be sufficient anymore in 2025 and will cause a large number of airside delays larger than 30 minutes, which are assumed to lead to

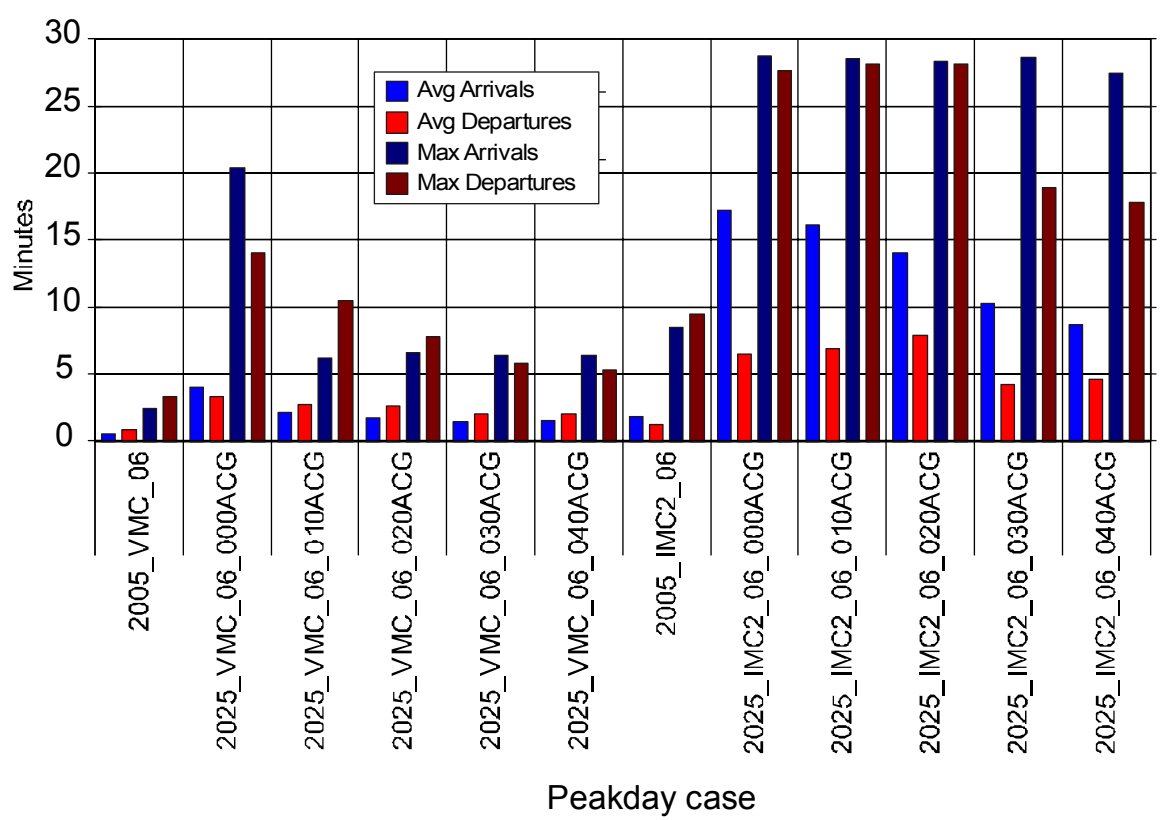

Fig. 8: Delay in for runway configuration 6

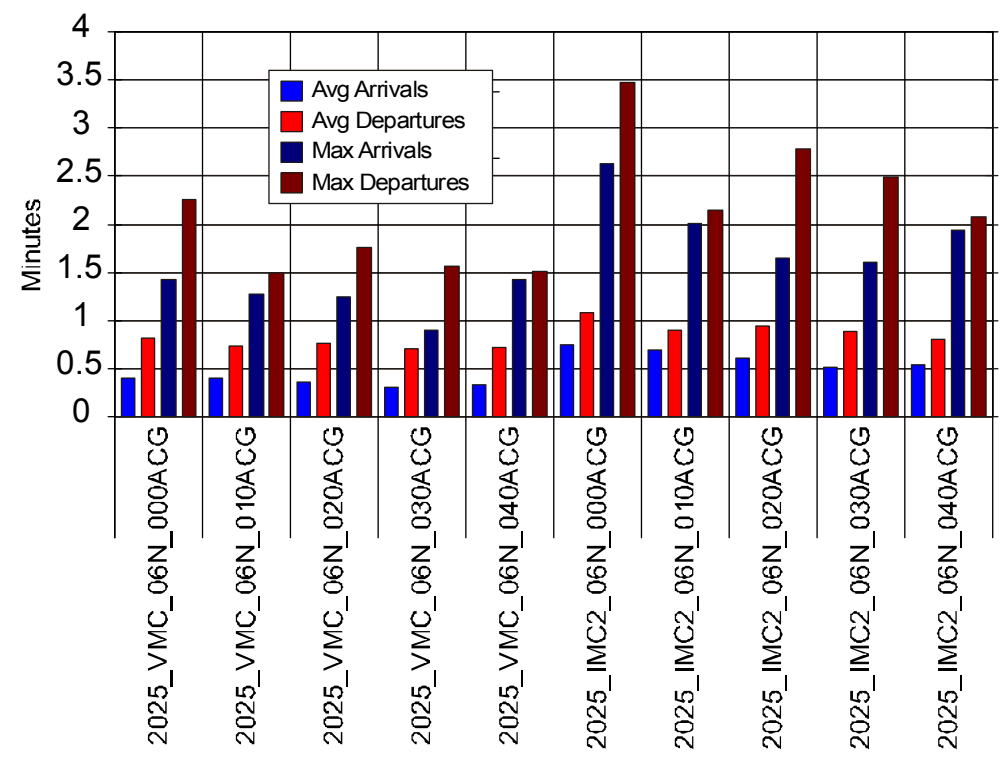

Fig. 7: Delay with an additional 06-runway 
cancelations. An extra north south runway is therefore advisable before 2025. Adding an additional closely spaced parallel runway next to current runway $14 / 32$ will cause the delay for that configuration to become equal to the current configuration 06, which is shown in Fig. 7.

Fig. 7 shows the average and maximum delays for both 2005 and the scenarios for 2025 for both VMC and IFR using runway configuration 06 . Whilst the delay in VMC is higher for all the future cases, the delay decreases with a higher aircraft growth with maximum delays of less than 6 minutes per aircraft for the 40 percent aircraft growth scenario. For IMC the delays are significantly higher and will cause some flights to be cancelled, though the 40 percent aircraft growth scenario does stay within reasonable limits, with an average arrival delay of less than 10 minutes. Adding an addition runway next to the current $06 / 24$ parallel runways would allow delays to drop even more, as can be seen in Fig. 8. Even in IFR conditions and low aircraft growth rates maximum delays then stay well below 3.5 minutes per aircraft. Because the occurrence of these conditions and the reduction in the average delay is limited, the costs of adding the extra runway do most probably not justify the cost.

\section{Noise Results}

ABS allows the data from ABS to be exported to the Federal Aviation Authority (FAA) Integrated Noise Model (INM). To get the aggregated noise result for a year, the traffic of every scenario is distributed over the four different runway configurations. Is assumed that configuration 06 is used 75 percent of the time, configuration 2415 percent of the time, configuration 147 percent of the time and configuration 323 percent of the time. The calculations are also run for the four different runway configurations, including configurations making use of both additional future runways. The average day schedule is assumed to represent 80 percent of the load of the peak day schedule. Whilst this is a simplification, the results will at least have relative value.

The tracks assumed for the flight path calculations are also simplified. For arrivals only a single 30 mile straight in arrival track is assumed and for departures one track is assumed for departures to each the north, east, south and west. No noise abatement procedures are taken into account. Also so called 'standard' arrival and departure profiles are assumed for all aircraft.

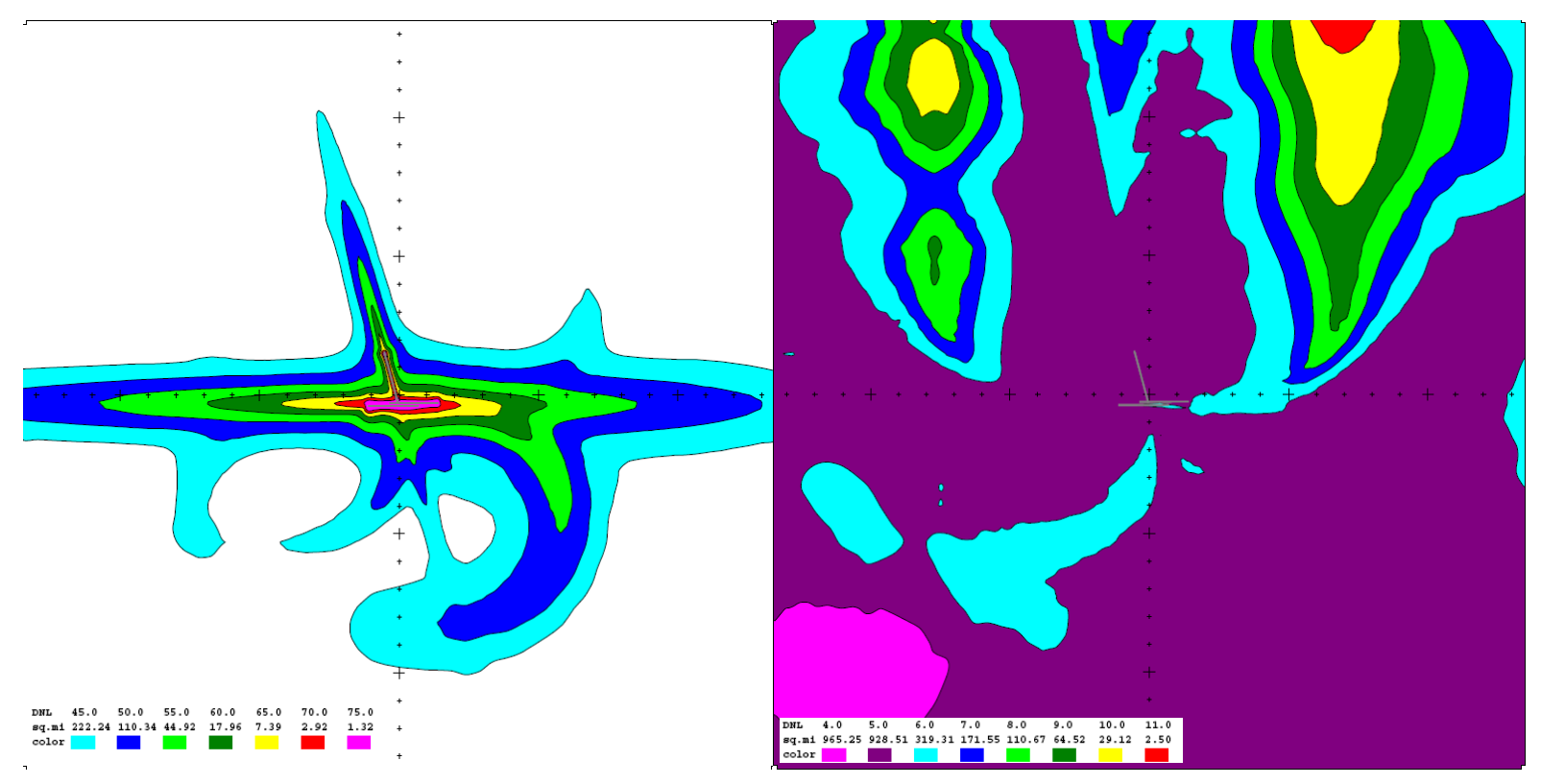

Fig. 9: Noise Contour 2005 (left) and difference contour 2025 0\% ACG 


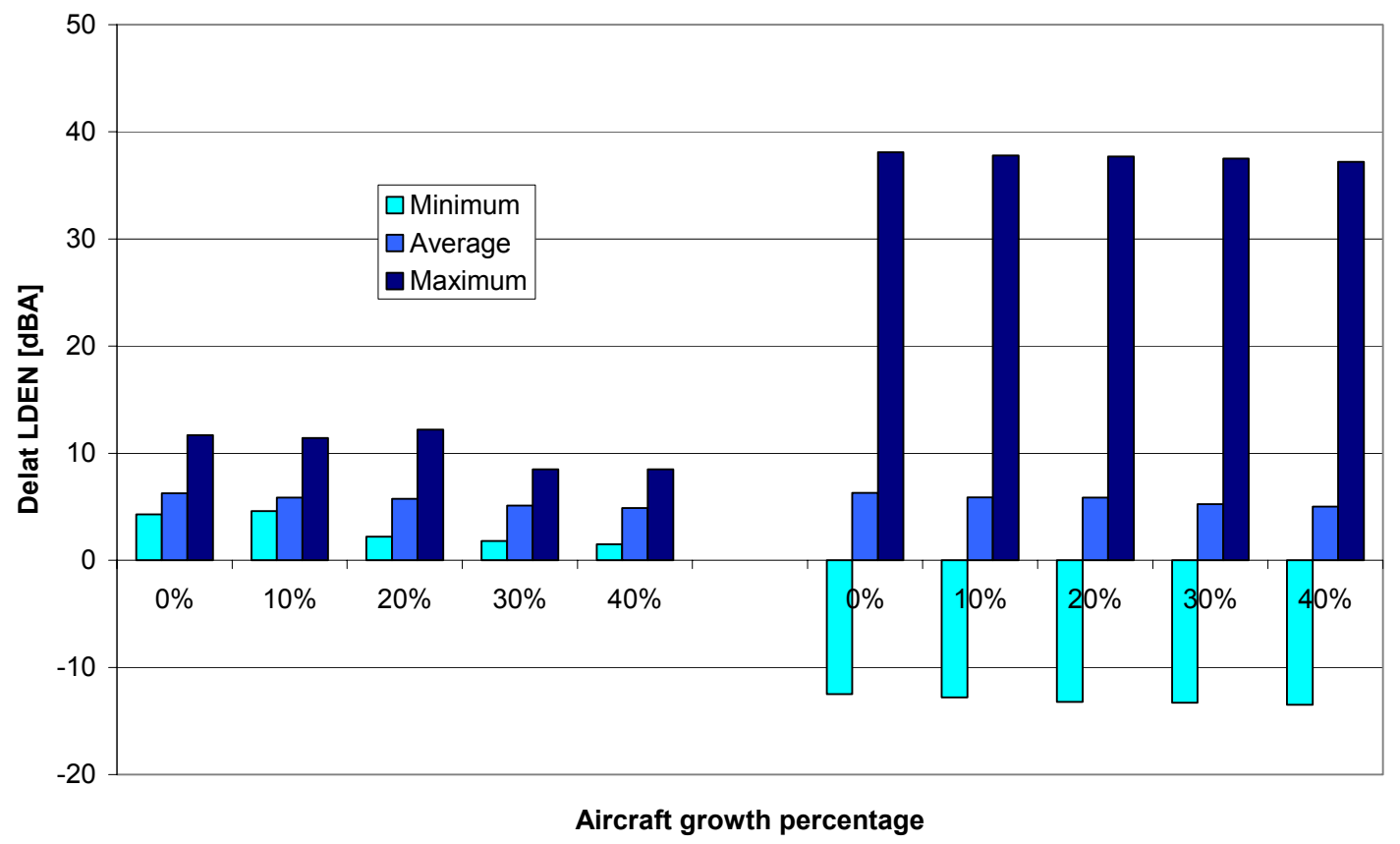

\section{Fig. 10: Summary of the difference contours for the different aircraft growth percentages without (left) and with (right) the new runways.}

For each future case in INM a contour of 50 by 50 kilometers and a grid of the same size divided into blocks of 250 by 250 meters is calculated and a difference contour is made with the base year. Fig. 9 shows the contour as calculated for the base year and the difference contour of the 20250 percent aircraft growth scenario, without additional runways, and the base year. As can be seen most of the area around the airport suffers at least a $4 \mathrm{~dB}$ increase in annual noise due to the increased traffic for the 0 percent aircraft growth scenario.

Fig. 10 shows a summary of all the results with respect to the minimum, average and maximum changes in calculated grid for the different aircraft growth scenarios. While all different aircraft growth scenarios result in an increase in average noise levels, the amount does reduce with higher aircraft growth. Even though the average levels are about the same as for the current runways, adding additional runways causes the noise annoyance to shift, which causes some areas to experience more noise and others to experience less noise, as can be seen by the low minimum changes and high maximum changes. Special attention should be given to the tracks for the new runway to assure that the large increases in noise levels do not fall in populated or other noise sensitive areas.
It should be noted that the replacement of aircraft in this study by newer aircraft is quite limited, and thus the overall noise levels should be expected to be significantly lower.

\section{Conclusions}

Results show that, with the current runway system, airside capacity will decrease significantly due to the increase in average aircraft size which is caused by to the relatively high level of expected growth in the cargo market.

An extra runway is needed in 2025 to cope with weather conditions that allow only runway $14 / 32$ to be used. An extra runway in east-west conditions does not seem to be necessary at that time, except if delays under instrumental meteorological conditions are also deemed important.

With respect to noise, the noise levels are expected to increase around the airport, though an increase in the average aircraft size does seem to limit this effect and the effects will probably be less than expected due to the advent to newer, quieter, aircraft. Special care should be taken if additional runways are added that these do not cause extra noise annoyance in populated or other noise sensitive areas. 


\section{References}

[1] Roling, P.C., The effects of fleet developments on airport congestion and environmental impact. 6th AIAA Aviation Technology, Integration and Operations Conference, 25-27 September 2006, Wichita, Kansas.

[2] Roling, P.C., Evaluation of London Heathrow using the airport business suite. 7th AIAA Aviation Technology, Integration and Operations Conference, 18-20 September 2007, Belfast, Northern Ireland.

[3] W.E. Walker, N.A. Lang, J. Keur, H.G. Visser, R.A.A. Wijnen, U. Kohse, J. Veldhuis, A.R.C. De Haan, An Organizational Decision Support System for Airport Strategic Exploration. in Tung Bui, Henryk Sroka, Stanislaw Stanek, and Jerzy Goluchowski (eds.), DSS in the Uncertainty of the Internet Age, Publisher of the Karol Adamiecki University of Economics in Katowice, Katowice, Poland, 2003, pp. 435-452.

[4] Roling, P.C., Hebly S., Wijnen, R. and Visser, D, Strategic Planning for Airport Systems: An educational perspective. $45^{\text {th }}$ AIAA Aerospace Sciences meeting and Exhibit, 8-11 January 2007, Reno, Nevada.

[5] Roling, P.C. \& Wijnen, R.A.A., Improvements to the airport business suite: A decision support system for airport development, planning and operations. Proceedings of the 1st Int. Conf. Research in Air Transport, pp. 73-84.

[6] HNTB corporation, Ted Stevens international airport master plan. November 2002

[7] HNTB corporation, Ted Stevens Anchorage international airport master plan (update), February 2007

[8] Airports Council International (http://www.airports.org/)

\section{Copyright Statement}

The authors confirm that they, and/or their company or institution, hold copyright on all of the original material included in their paper. They also confirm they have obtained permission, from the copyright holder of any third party material included in their paper, to publish it as part of their paper. The authors grant full permission for the publication and distribution of their paper as part of the ICAS2008 proceedings or as individual off-prints from the proceedings. 